\title{
Characterization of Aura TES carbonyl sulfide retrievals over ocean
}

\author{
L. Kuai ${ }^{1}$, J. Worden ${ }^{2}$, S. S. Kulawik ${ }^{2}$, S. A. Montzka ${ }^{3}$, and J. Liu ${ }^{1}$ \\ ${ }^{1}$ California Institute of Technology, Pasadena, California, USA \\ ${ }^{2}$ Jet Propulsion Laboratory, California Institute of Technology, Pasadena, California, USA \\ ${ }^{3}$ Global Monitoring Division, NOAA Earth System Research Laboratory, Boulder, Colorado, USA \\ Correspondence to: L. Kuai (lkuai@jpl.nasa.gov)
}

Received: 5 July 2013 - Published in Atmos. Meas. Tech. Discuss.: 31 July 2013

Revised: 4 November 2013 - Accepted: 5 December 2013 - Published: 22 January 2014

\begin{abstract}
We present a description of the NASA Aura Tropospheric Emission Spectrometer (TES) carbonyl sulfide (OCS) retrieval algorithm for oceanic observations, along with evaluation of the biases and uncertainties using aircraft profiles from the HIPPO (HIAPER Pole-to-Pole Observations) campaign and data from the NOAA Mauna Loa site. In general, the OCS retrievals (1) have less than 1.0 degree of freedom for signals (DOFs), (2) are sensitive in the mid-troposphere with a peak sensitivity typically between 300 and $500 \mathrm{hPa}$, (3) but have much smaller systematic errors from temperature, $\mathrm{CO}_{2}$ and $\mathrm{H}_{2} \mathrm{O}$ calibrations relative to random errors from measurement noise. We estimate the monthly means from TES measurements averaged over multiple years so that random errors are reduced and useful information about OCS seasonal and latitudinal variability can be derived. With this averaging, TES OCS data are found to be consistent (within the calculated uncertainties) with NOAA ground observations and HIPPO aircraft measurements. TES OCS data also captures the seasonal and latitudinal variations observed by these in situ data.
\end{abstract}

\section{Introduction}

Carbonyl sulfide (OCS) significantly influences the sulfur cycle (Ko et al., 2003; Notholt et al., 2003, 2006; Montzka et al., 2007). It has a greenhouse gas effect based on absorption of far-infrared radiation (Brühl et al., 2012). OCS is also found as a potential trace gas, other than carbon dioxide, that could provide independent information about carbon cycle processes (Montzka et al., 2007; Campbell et al., 2008; Suntharalingam et al., 2008; Wohlfahrt et al., 2012; Blonquist et al., 2011; Berry et al., 2013). For example, recent work by Campbell et al. (2008) suggests that carbonyl sulfide is a good photosynthetic tracer. A study by Asaf et al. (2013) concludes that OCS flux could provide a constraint on estimates of gross primary productivity (GPP).

Carbonyl sulfide sources and sinks, however, are poorly quantified (Montzka et al., 2007). The major source of atmospheric carbonyl sulfide comes from the ocean (Cutter et al., 2004), but other sources include wetlands, soil and precipitation, biomass burning, volcanoes, anthropogenic activities, and oxidation of carbon disulfide and dimethyl sulfide (Montzka et al., 2007; Watts, 2000). The primary sinks of carbonyl sulfide are vegetation, soil and photochemical loss (Montzka et al., 2007).

The mixing ratio of OCS in the troposphere is about $500 \mathrm{ppt}$ (parts per trillion) and OCS is generally well mixed over the ocean and decreases rapidly with altitude in the stratosphere (Chin and Davis, 1995; Notholt et al., 2003; Barkley et al., 2008). However, latitudinal, seasonal, and longitudinal variations are about $10 \%$ or even larger over land. Earlier studies have reported a slow decline in OCS mixing ratios in both hemispheres since the 1980s (Rinsland et al., 2002, 2008; Montzka et al., 2004; Mahieu et al., 2003). A recent study of one individual ground-based site, however, suggests no consistent trend during the period of February 2000February 2005 (Montzka et al., 2007).

Atmospheric OCS concentrations in the free troposphere and boundary layer are currently measured at ground stations, tall towers, and aircraft using flask sampling or continuous measuring equipment. The NOAA-ESRL global monitoring network provides continuous records of OCS at 14 sampling sites (Montzka et al., 2007). The first satellite retrievals of carbonyl sulfide were based on solar occultation observations of the upper troposphere and stratosphere 
made by the Atmospheric Chemistry Experiment Fourier Transform Spectrometer (ACE-FTS) (Barkley et al., 2008). These observations during 2004-2006 provided an estimate of the stratospheric lifetime of OCS along with concurrent measurements of chlorofluorocarbons (CFCs). In this paper, we evaluate free tropospheric OCS measurements from the Aura Tropospheric Emissions Spectrometer (TES) over ocean scenes. The Aura TES instrument is a highresolution infrared-imaging Fourier transform spectrometer (Beer, 2006; Bowman et al., 2006). To evaluate the performance of algorithms, the TES free tropospheric OCS is compared with the independent NOAA observations from a ground-based site at Mauna Loa (MLO) (Montzka et al., 2007) and the measurements also made by the same NOAA laboratory during the HIAPER Pole-to-Pole Observations (HIPPO) flights (Wofsy et al., 2011).

\section{Retrieval strategy}

\subsection{Retrieval methodology}

The TES OCS retrieval is based on an optimal estimation (O.E.) approach (Rodgers, 2000) by fitting calculated spectra from a nonlinear radiative transfer model driven by the atmospheric state to the TES observed spectral radiances. The estimated state is also constrained by an a priori based on its probability distribution for that state in order to ensure a meaningful result (Bowman et al., 2006). The goal of this approach is to minimize the cost function, $\chi(\boldsymbol{x})$ :

$$
\begin{gathered}
\chi(\boldsymbol{x})=\left(\boldsymbol{y}_{\mathrm{m}}-\boldsymbol{y}_{\mathrm{o}}\right)^{\mathrm{T}} \mathbf{S}_{\mathrm{n}}^{-1}\left(\boldsymbol{y}_{\mathrm{m}}-\boldsymbol{y}_{\mathrm{o}}\right) \\
+\left(\hat{x}-\boldsymbol{x}_{\mathrm{a}}\right)^{\mathrm{T}} \mathbf{S}_{\mathrm{a}}^{-1}\left(\hat{x}-\boldsymbol{x}_{\mathrm{a}}\right),
\end{gathered}
$$

where $\hat{x}, \boldsymbol{x}_{\mathrm{a}}$ and $\boldsymbol{x}$ are the retrieved, a priori, and the "true" state vectors respectively. They are expressed in natural logarithm of volume mixing ratio. $\boldsymbol{y}_{\mathrm{m}}$ and $\boldsymbol{y}_{\mathrm{o}}$ are model calculated and observed spectral radiance. $\mathbf{S}_{\mathrm{n}}^{-1}$ and $\mathbf{S}_{\mathrm{a}}^{-1}$ are inversion of the covariance matrix for measurement noise and a priori for the retrieved state vectors. If a minimum to the cost function is found then the estimated state vector can be related to the true state vector in the following manner (Rodgers, 2000):

$\hat{x}=\boldsymbol{x}_{\mathrm{a}}+\mathbf{A}\left(\boldsymbol{x}-\boldsymbol{x}_{\mathrm{a}}\right)+\mathbf{G n}+\mathbf{G K}_{b}\left(\boldsymbol{b}-\boldsymbol{b}_{\mathrm{a}}\right)$,

where $\boldsymbol{n}$ is a vector of measurement noise on the spectral radiances. $\boldsymbol{b}$ and $\boldsymbol{b}_{\mathrm{a}}$ represent the true state and a priori for those parameters that are not retrieved but also affect the model radiance. The sensitivities of the radiance to those parameters (Jacobians) are $\mathbf{K}_{b}=\frac{\partial \boldsymbol{y}}{\partial \boldsymbol{b}}$, the dependence of the radiance $(\boldsymbol{y})$ on the interfering parameter $(\boldsymbol{b})$. $\mathbf{G}$ is the gain matrix, which is defined by

$\mathbf{G}=\frac{\partial \boldsymbol{x}}{\partial \boldsymbol{y}}=\left(\mathbf{K}^{T} \mathbf{S}_{\mathrm{n}}^{-1} \mathbf{K}+\mathbf{S}_{\mathrm{a}}^{-1}\right)^{-1} \mathbf{K}^{T} \mathbf{S}_{\mathrm{n}}^{-1}$.
G maps from measurement (spectral radiance) space into retrieval space. $\mathbf{K}=\frac{\partial \boldsymbol{y}}{\partial \boldsymbol{x}}$ defines the Jacobians for the retrieved state vectors. A is the averaging kernel matrix, which describes the sensitivity of the retrieved state vector to the true state.

$\mathbf{A}=\frac{\partial \hat{x}}{\partial \boldsymbol{x}}=\mathbf{G K}$.

The trace of the averaging kernel gives the number of degrees of freedom for signals (DOFs) from the retrieval.

The carbonyl sulfide retrievals are carried out after the retrievals of temperature, water vapor, ozone, carbon monoxide, carbon dioxide, methane, surface temperature, emissivity, cloud optical depth, and cloud pressure (Kulawik et al., 2006). We only perform retrievals for scenes with a cloud optical depth of less than 0.5 as clouds reduce the sensitivity of observed radiance to atmospheric OCS. Adjustments to the atmospheric $\mathrm{CO}_{2}, \mathrm{H}_{2} \mathrm{O}$, surface temperature, cloud optical depth, and cloud pressure are applied simultaneously with the OCS retrieval.

\subsection{TES OCS spectral windows}

Figure 1a shows the OCS absorption spectral region from 2034 to $2075 \mathrm{~cm}^{-1}$. In order to show the impact of the OCS lines on the radiances, we compute simulated radiances using the geophysical parameters affecting the observed radiance (e.g., water vapor, $\mathrm{CO}_{2}, \mathrm{CO}$, ozone, surface temperature, cloud optical depth, cloud pressure, and emissivity) and the OCS profile. Then we repeat the calculations with the same atmosphere but without OCS (Fig. 1a). The residuals of the two radiances are shown in Fig. 1b, which illustrates the absorption by OCS. This figure gives also the OCS vertically integral Jacobians. The contour plot of OCS Jacobians (Fig. 1c) suggests that the radiances are most sensitive to OCS between 900 and $200 \mathrm{hPa}$. Figure $1 \mathrm{~b}$ shows that the signal at the spectral region with strong OCS absorption is about the same or even larger than the noise equivalent spectral radiance (NESR), $1 \times 10^{-8} \mathrm{~W} \mathrm{~cm}^{-2} \mathrm{sr}^{-1} \mathrm{~cm}^{-1}$. Consequently, the OCS signal is detectable from the TES measured radiance with the current noise level.

Figure 1d shows the vertically integral Jacobians of the absorption gases in addition to OCS at this spectral region. Water vapor (blue line) and $\mathrm{CO}_{2}$ (green line) are dominant in this spectral region. $\mathrm{CO}$ and ozone are active on some spectral lines. For these reasons, $\mathrm{CO}_{2}$ and $\mathrm{H}_{2} \mathrm{O}$ are simultaneously retrieved with OCS but are tightly constrained. The a priori profiles for $\mathrm{CO}_{2}$ and $\mathrm{H}_{2} \mathrm{O}$ are estimated from previous retrieval steps, using their absorption bands that are also measured by TES (Kulawik et al., 2010; Worden et al., 2004). The constraint matrices for $\mathrm{CO}_{2}$ and $\mathrm{H}_{2} \mathrm{O}$ are based on the covariance from their previous estimates. $\mathrm{CO}$ concentrations are not jointly retrieved with OCS but have been estimated previously using the $\mathrm{CO}$ band near $2100 \mathrm{~cm}^{-1}$ (Worden et al., 2004). 

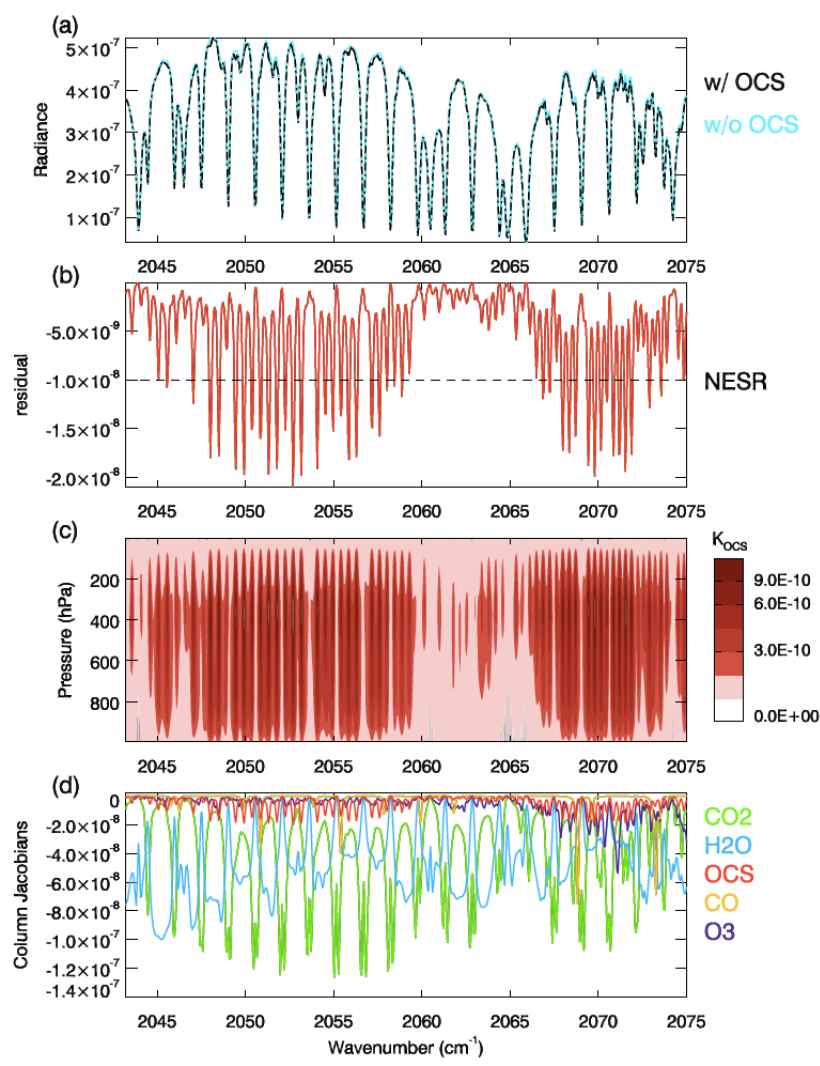

Fig. 1. (a) Model calculated radiances without OCS profile (blue line) and with OCS profile (black-dash line); (b) residuals between the two models' calculated radiances in (a); the red line is the OCS vertically integral Jacobians in (d); the dash line represents the noise equivalent spectral radiance (NESR), $1 \times 10^{-8} \mathrm{~W} \mathrm{~cm}^{-2} \mathrm{sr}^{-1} \mathrm{~cm}^{-1}$; (c) contour plot for OCS Jacobians; (d) vertically integral Jacobians for $\mathrm{CO}_{2}$ (green), $\mathrm{H}_{2} \mathrm{O}$ (blue), OCS (red), $\mathrm{CO}$ (orange) and $\mathrm{O}_{3}$ (purple).

\subsection{A priori vectors and constraints}

In addition to OCS, we also simultaneously retrieve surface temperature, $\mathrm{H}_{2} \mathrm{O}, \mathrm{CO}_{2}$, cloud optical depth, and cloud pressure level. If over land, emissivity is also required to be retrieved for that spectral region. In this paper, we only report the retrievals over ocean. We do not take into account the impact of aerosols on OCS retrievals since the spectral region we use is from the mid-infrared region and aerosols from biomass burning negligibly affect the retrievals (Shephard et al., 2011; Verma et al., 2009; Worden et al., 2013). Although significant dust from the desert could affect mid-IR (infrared) retrievals, the current study is limited to over the Pacific and aerosols there are mostly from biomass burning.

The a priori profile of OCS is set to a constant value of $500 \mathrm{ppt}$ in the free troposphere and decreases with altitude above the tropopause (Fig. 2). No obvious long-term trend is observed in atmospheric OCS, so at this stage we simply use
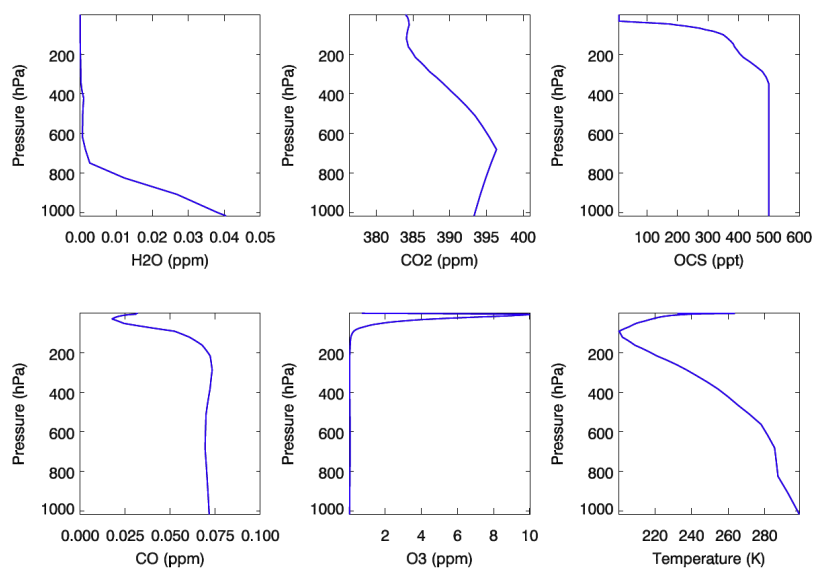

Fig. 2. Examples of $\mathrm{H}_{2} \mathrm{O}, \mathrm{CO}_{2}$, and OCS a priori profiles on the top and the state of other variables (e.g., $\mathrm{CO}, \mathrm{O}_{3}$, and temperature) on the bottom.

a common OCS a priori profile to ensure that the retrieved spatiotemporal variations are not coming from the a priori.

Typically for an O.E. retrieval, the covariance of the $\mathbf{S}_{\mathrm{a}}$ term describes the expected statistics of the retrieved parameter and also acts to constrain the values that are allowed for the estimate. However, we relax this term for the OCS retrievals in order to increase sensitivity of the estimated OCS to true OCS variations at the expense of increasing errors from random noise or interferences (Worden et al., 2010). This approach works for OCS because, as demonstrated in Sect. 3.2, the uncertainties are dominated by noise. Errors from interferences such as temperature and $\mathrm{H}_{2} \mathrm{O}$, which can affect the observed variability of the OCS estimates, are found to be much smaller than the noise-based error. Consequently, we can average the OCS estimates as the uncertainties are effectively random. Figure 3 shows the square roots of the diagonals of the covariance matrices. The dots on the profile indicate the retrieval levels. Note that the covariance matrices are calculated in natural logarithm; consequently, the values are in percentage.

\section{TES carbonyl sulfide product}

\subsection{TES OCS detection limits and retrieval characteristics}

Figure 4 shows comparisons of TES observed radiances near Mauna Loa with modeled radiances that depend on the set of geophysical parameters affecting the observed radiance. We choose two examples of TES observations. " $\mathrm{d} 1=\boldsymbol{y}_{\mathrm{o}}-$ $\boldsymbol{y}_{\mathrm{m}}\left(\mathrm{H}_{2} \mathrm{O}, \mathrm{CO}_{2}\right)$ " (light blue in Fig. 4a, c) is the difference between the measured TES spectra and the forward model run driven by the retrieved variables such as $\mathrm{H}_{2} \mathrm{O}, \mathrm{CO}_{2}$ but no OCS. "d $2=\boldsymbol{y}_{\mathrm{m}}\left(\mathrm{H}_{2} \mathrm{O}, \mathrm{CO}_{2}, \mathrm{OCS}\right)-\boldsymbol{y}_{\mathrm{m}}\left(\mathrm{H}_{2} \mathrm{O}, \mathrm{CO}_{2}\right)$ " ( $($ red in Fig. $4 \mathrm{a}, \mathrm{c})$ is the difference between the two forward model 

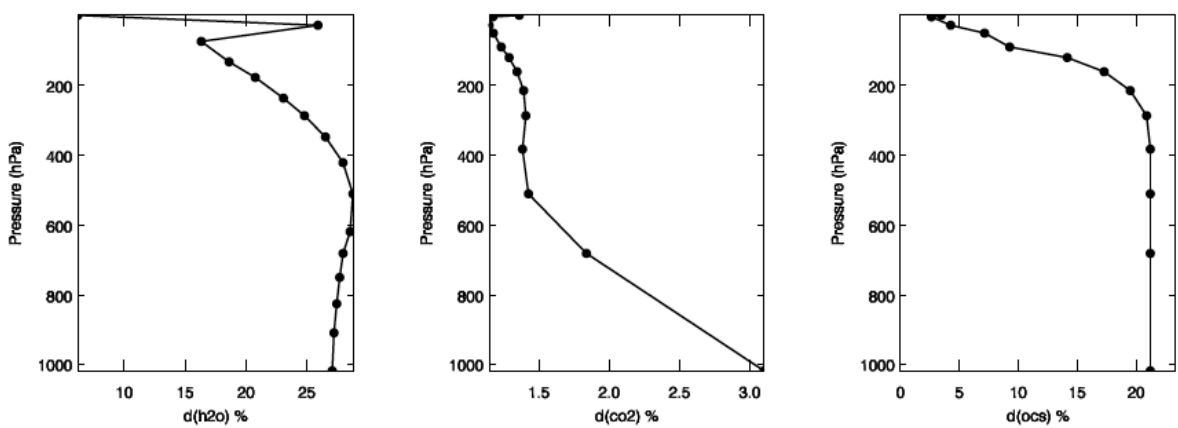

Fig. 3. Square root of the diagonal values of the covariance matrices for $\mathrm{H}_{2} \mathrm{O}, \mathrm{CO}_{2}$, and $\mathrm{OCS}$.

runs with and without OCS or considered as the vertically integral Jacobians of OCS. The spikes in $\mathrm{d} 1$ are related to the OCS absorption in $\mathrm{d} 2$, which suggests that without the simulation of the absorption by OCS, the residuals (d1) are not only the measurement noise but also the absorption by OCS (d2). Then, we show the residuals after the OCS retrieval $\left(\mathrm{d} 3=\boldsymbol{y}_{\mathrm{o}}-\boldsymbol{y}_{\mathrm{m}}\left(\mathrm{H}_{2} \mathrm{O}, \mathrm{CO}_{2}, \mathrm{OCS}\right)\right.$, the light blue lines with dots in Fig. 4b, d). The spikes related to OCS absorption are no longer shown in $\mathrm{d} 3$ and the residuals randomly vary about zero. Dots on $\mathrm{d} 3$ indicate the frequency of the channels selected for the retrievals.

Figure $4 \mathrm{a}$ and $\mathrm{b}$ represent an atmosphere with low OCS concentrations so the OCS signal (d1 in red line) is weak, about or even below the noise level (dashed lines). Figure 4c and $\mathrm{d}$ show strong OCS signals. If OCS is not retrieved with these radiances, the residuals (d1) are biased below zero, especially at the region with strong OCS absorption lines near 2050 and $2070 \mathrm{~cm}^{-1}$. With the OCS retrieval, however, the residuals (d3) are much more random and symmetric about zero.

Due to the low sensitivity of the TES observed radiances to OCS, the TES spectrum gives limited information about the OCS profile. Therefore, we vertically average the TES retrieval. In general, under clear-sky conditions, TES estimates are sensitive to the OCS distribution from 900 to $200 \mathrm{hPa}$ with a peaked sensitivity near $400 \mathrm{hPa}$. The sensitivity of the OCS estimate is primarily determined by the surface temperature and thermal contrast between surface and atmospheric temperature. Figure 5a shows the averaging kernels at different vertical levels for a single sounding retrieval. This figure suggests that the OCS retrieval sensitivity peaks in the midtroposphere. The DOFs for this retrieval are 0.67. The retrieved OCS profile is plotted in Fig. 5b as a black line with dots. Because OCS is well mixed in the free troposphere and the analysis of averaging kernel suggests that TES OCS estimates are most sensitive to a vertical range centered near $400 \mathrm{hPa}$, with less than $1 \mathrm{DOFs}$, we use the average of the retrieved OCS between 900 and $200 \mathrm{hPa}$ to represent the TES retrieved tropospheric OCS (red in Fig. 5b).
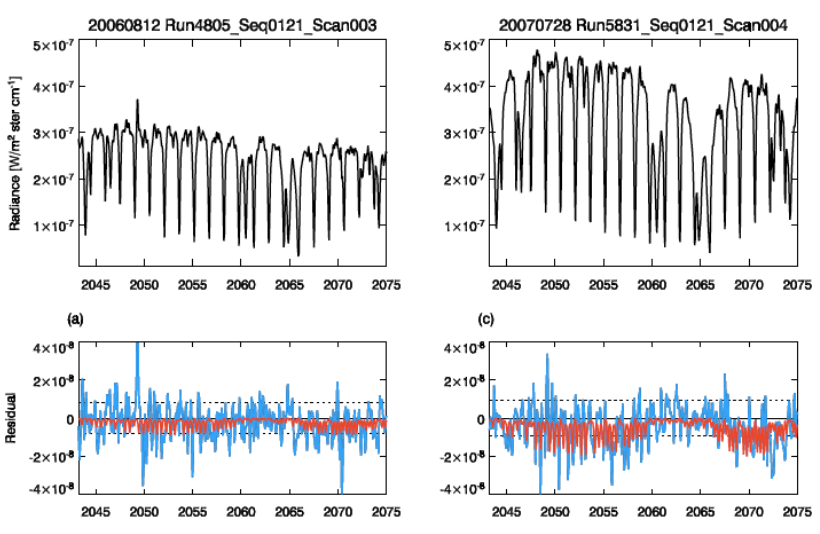

(c)

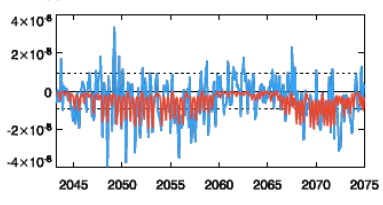

(b)
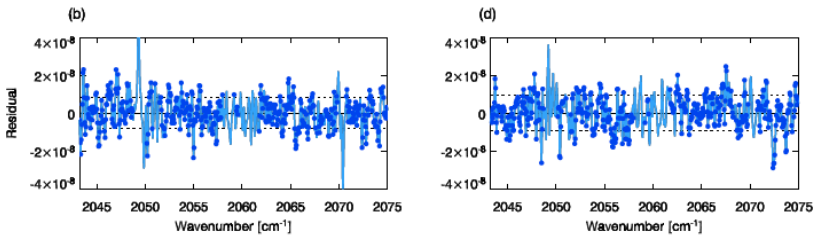

Fig. 4. Carbonyl sulfide spectral signal in the TES observations. The top two panels are the TES measured spectra for OCS retrievals. In (a) and (c), light blue lines without dots (d1) are the differences between TES measured spectra and forward-model run driven by retrieved $\mathrm{CO}_{2}$ and $\mathrm{H}_{2} \mathrm{O}$ but no OCS; red lines (d2) are differences between two forward-model runs with and without OCS or can be considered as OCS vertically integral Jacobians. In (b) and (d) shown in light blue lines with dots (d3) are the residuals after OCS retrieval. Dots indicate the frequencies of the channels used for retrieval. Solid black lines are the zero lines and dashed lines represent the noise level (NESR).

\subsection{Retrieval error analysis}

Figure 6 shows the reduction of the uncertainties after the TES retrieval by comparing the a posteriori uncertainties (or total error, dashed line) to the a priori uncertainties (black line with dots). The total error for an individual retrieval, however, is still quite large and ranges from 50 to $80 \mathrm{ppt}$, almost of the same order of magnitude as for the OCS seasonal variations in the Northern Hemisphere. Fortunately, 

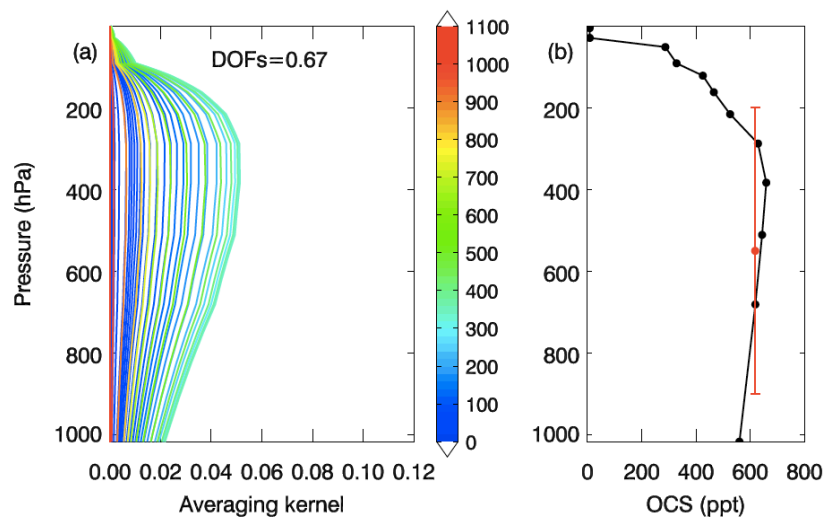

Fig. 5. (a) Averaging kernels for different vertical levels in colored lines. (b) Retrieved OCS profile (black line with dots) and its corresponding tropospheric OCS in red.

the dominant errors come from measurement noise and are therefore random. The primary three systematic errors due to $\mathrm{CO}_{2}, \mathrm{H}_{2} \mathrm{O}$ and temperature are much smaller $(<5 \mathrm{ppt})$ than the measurement error, therefore we plot the original values multiplied by ten in Fig. 6. The error analysis suggests that by averaging a large number of retrievals, for example averaging the monthly data over multiple years, the total error can be greatly reduced.

\subsection{Quality assessment of the TES product and the bias correction}

To evaluate the performance of the TES OCS retrieval we perform a comparison of monthly means over multiple years between the in situ data and the TES retrieved estimates for seasonal variability over Mauna Loa and for latitudinal gradients over the Pacific region. As shown in the previous section systematic errors from radiative interferences such as $\mathrm{H}_{2} \mathrm{O}$, $\mathrm{CO}_{2}$, and temperature are small, i.e., less than 5 ppt. Measurement noise is the largest uncertainty of the OCS estimates (not including "smoothing" error). This measurement noise is random and consequently the OCS estimates can be averaged with a reduction of error corresponding to the square root of the number of observations. Additionally, averaging over multiple years we gain sensitivity to seasonal and latitudinal variations with the TES data.

By applying the TES averaging kernel, A, and a priori, $\chi_{\mathrm{a}}$, to the in situ observed concentration profile $\left(\chi_{\mathrm{std}}^{\mathrm{OCS}}\right)$ in logarithm, we can perform the comparison between the TES tropospheric OCS and vertically convolved observations that accounts for the a priori regularization together with the sensitivity and vertical resolution of the TES retrievals:

$\ln \left(\chi_{\text {std_AK }}^{\text {OCS }}\right)=\ln \left(\chi_{\mathbf{a}}\right)+\mathbf{A}\left(\ln \left(\chi_{\text {std }}^{\text {OCS }}\right)-\ln \left(\chi_{\mathrm{a}}\right)\right)$.

Comparisons between the TES OCS retrievals and the HIPPO aircraft (after applying the TES operator to the

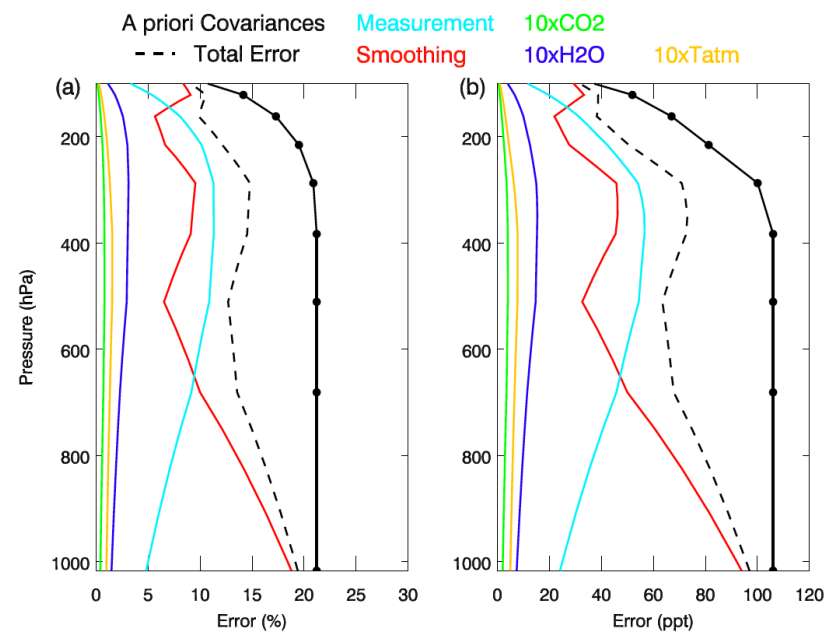

Fig. 6. Estimated errors for a single sounding retrieval near Mauna Loa. The nonoptimal assumed variability used to constrain the OCS retrieval is the black line with dots. The a posteriori total error is composed of smoothing error (red), measurement error (light blue), and systematic errors due to $\mathrm{H}_{2} \mathrm{O}$ (dark blue), $\mathrm{CO}_{2}$ (green) and atmospheric temperature (yellow). Note that since the systematic error owing to other trace gases or temperature is quite small compared to other errors, we multiply the errors by ten. (a) Errors in percentage. (b) Errors in units of ppt.

HIPPO data) indicate that the TES OCS retrievals are biased high by $13 \%$. The $13 \%$ bias could be a combination of the following effects: (1) the spectroscopic uncertainties in the OCS line parameters, (2) instrument calibration uncertainty, (3) effects of ignoring the solar contribution in the forward model, and (4) errors from interfering species (e.g., $\mathrm{CO}_{2}$, $\mathrm{H}_{2} \mathrm{O}, \mathrm{CO}$ and $\mathrm{O}_{3}$ ). The current TES retrieval algorithm uses the forward model based on the HITRAN 2008 database. The uncertainty for OCS intensities in HITRAN 2008 ranges from 2 to $20 \%$. Attempting to quantify each of these effects is beyond the scope of this paper.

The correction for this bias must therefore account for the sensitivity of the retrieval. For example, if the TES OCS estimate shows zero sensitivity, the estimate will return to the a priori constraint regardless of the spectroscopic uncertainties. For this reason we use the following form to estimate the bias correction by fitting the resulting observed OCS $\left(\chi_{\text {corrected }}^{\text {OCS }}\right)$ with TES OCS, as discussed in Worden et al. (2006):

$\operatorname{Mln}\left(\chi_{\text {corrected }}^{\text {OCS }}\right)=\mathbf{M} \ln \left(\chi_{\text {std_AK }}^{\text {OCS }}\right)+\mathbf{M A}\left(\boldsymbol{\delta}_{\text {bias }}\right)$,

where $\chi_{\text {std_AK }}^{\mathrm{OCS}}$ is the volume mixing ratio from the groundbased or flight observations already convolved with TES averaging kernel using Eq. (5). $\mathbf{A}$ is the TES OCS averaging kernel matrix. The bias correction factor $\left(\boldsymbol{\delta}_{\text {bias }}\right)$ is estimated to be 0.52 by comparing between HIPPO and TES data as discussed next. $\mathbf{M}$ is a mapping operator to average 
the profile between 900 and $200 \mathrm{hPa}$. The process of applying Eqs. (5) and (6) to in situ data is referred to the TES operator.

\subsubsection{Latitudinal gradient over the Pacific}

The multiyear TES OCS monthly means are compared to the measurements from five HIPPO aircraft campaigns to study the latitudinal variability during different seasons across the Pacific Ocean. We only used the HIPPO OCS measurements by NWAS-M2 (NOAA Whole Air Sampler - Mass Spectrometer \#2), one of their three instruments (OCS_M2 data from HIPPO NOAA Flask Sample GHG, Halocarbon, And Hydrocarbon Data in file HIPPO_noaa_flask_allparams_merge_insitu_20121129.tbl; this data file can be downloaded at the website http://hippo.ornl.gov/dataaccess) (Wofsy et al., 2011).

The random errors of the TES OCS single-sounding retrieval averaged over the free troposphere can vary between 50 and 80 ppt. We must therefore average 150 or more of these retrievals in order to reduce uncertainty to less than $7 \mathrm{ppt}$, which should be a small enough error for the TES OCS data to capture the latitudinal and seasonal variability of tropospheric OCS concentrations observed by HIPPO and Mauna Loa data respectively. In addition, our approach for comparing between the in situ data and TES data is to assume that interannual variability for any given month is "small" (Montzka et al., 2007) so that we can average multiple years of TES data.

Prior to comparing the TES data to HIPPO, we first average all the TES data within $10^{\circ}$ latitudinal and longitudinal bins and also within \pm 15 days of each HIPPO profile measurement (Fig. 7 and Table 1). We choose $10^{\circ}$ as our bin size since it is small enough to capture the latitudinal variability of OCS but large enough to obtain a large number of TES retrievals in order to reduce the uncertainty of the average TES OCS within this bin to $7 \mathrm{ppt}$ or less. We use data from 2006 to 2010 for this comparison. For example, if a HIPPO measurement occurred on 15 November, the TES data between 1 November and 30 November for all $5 \mathrm{yr}$ are used in the comparison.

We must therefore average all the HIPPO OCS data in the free troposphere in these $10^{\circ}$ latitudinal bins (and corresponding month) to be consistent with the TES averaging. To reduce the effects variability from short timescale mixing processes, we also average the HIPPO OCS data vertically and then re-map to the TES grid pressure from the surface to $200 \mathrm{hPa}$.

Finally, the TES observation operator (averaging kernel, a priori constraint, and bias correction) from each TES retrieval within a given latitudinal/month bin is applied to the averaged HIPPO profile from the corresponding latitudinal/month bin. Note that this operation is equivalent to first averaging all of the TES observation operators together (within a bin) and applying this averaged TES observation operator to the averaged HIPPO profile. We only apply the
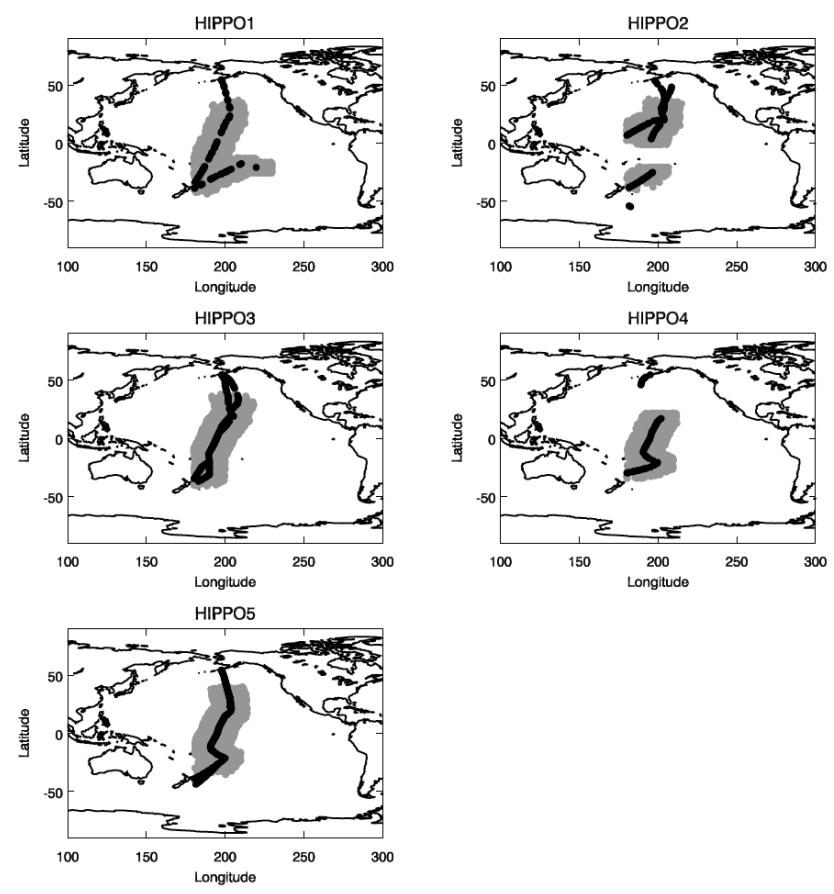

Fig. 7. HIPPO campaign trajectory in black dots. The gray region shows the coverage of overpassed TES measurements within the grid box of $\pm 10^{\circ}$ about each HIPPO measurement and during the \pm 15 day period of the years 2006-2010. Both of the HIPPO and TES OCS profiles are vertically averaged between 900 and $200 \mathrm{hPa}$ and latitudinally averaged onto regular grids from $35^{\circ} \mathrm{S}$ to $35^{\circ} \mathrm{N}$ every $10^{\circ}$.

TES operator up to $200 \mathrm{hPa}$ to mitigate the effect of uncertainties from the prior OCS in the stratosphere on the comparison (e.g., Worden et al., 2013).

We exclude retrievals over land, total SNR (signal-to-noise ratio) less than 40 , cloud optical depth greater than 0.5 , and retrieved chi-square outside the range of 0.8-1.2. With these quality flags, we generally exclude higher latitude or colder regions. Consequently, the latitudinal range of the TES and HIPPO comparisons vary from season to season.

Figure 8a-f show the comparisons between the TES and HIPPO data. The black line shows the HIPPO data, binned at $10^{\circ}$ latitude and averaged over the free troposphere. Corresponding TES data are in red. The blue points represent the mean of the HIPPO profile after the set of TES observation operators in the corresponding latitude bin has been applied to the HIPPO profile (representing by the black symbols). The red error bars are the error on the mean between the TES OCS estimates and the HIPPO estimate, after the TES observation operators have been applied. The red error bars represent the actual errors and are compared to the calculated errors in the next section.

The multiyear, monthly-averaged TES retrievals and results from the five HIPPO measurements applied with the TES operator in general exhibit similar latitudinal variations 
Table 1. List of the HIPPO measurement period, correlation coefficient, bias, SD, TES precision and sample number for the comparisons between TES multiyear monthly data and in situ data. The sample values listed here are the range of the numbers of TES retrievals in the grid boxes at different latitude bins.

\begin{tabular}{lrrrrrrr}
\hline In situ & HIPPO1 & HIPPO2 & HIPPO3 & HIPPO4 & HIPPO5 & MLO & All HIPPO \\
\hline Year & 2009 & 2009 & 2010 & 2011 & 2011 & $2006-2010$ & \\
First day & $01 / 14$ & $11 / 04$ & $03 / 29$ & $06 / 22$ & $08 / 22$ & $01 / 01$ & \\
Last day & $01 / 26$ & $11 / 19$ & $04 / 13$ & $07 / 07$ & $09 / 06$ & $12 / 31$ & \\
$R$ & 0.93 & 0.80 & 0.71 & 0.90 & 0.61 & 0.82 & 0.66 \\
Bias (ppt) & 2.34 & 7.63 & 0.22 & -2.30 & -5.55 & -14.91 & 0.06 \\
SD (ppt) & 8.14 & 7.49 & 6.35 & 8.01 & 5.12 & 4.69 & 7.74 \\
TES precision (ppt) & 4.45 & 4.50 & 4.71 & 4.55 & 3.84 & 7.30 & \\
TES sample number & $208-716$ & $153-505$ & $139-447$ & $293-428$ & $190-566$ & $77-174$ & \\
\hline
\end{tabular}
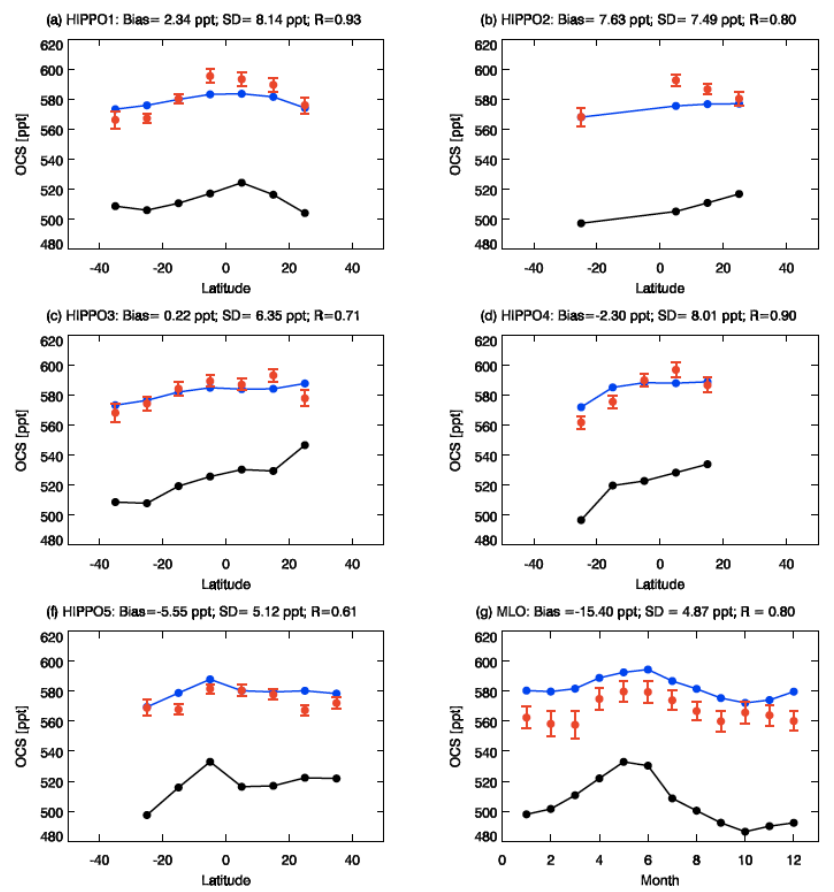

Fig. 8. Individual comparison between TES multiyear monthly means and in situ data for latitudinal patterns (a-f) and seasonal variations (g). Original in situ data averaged over latitude bins in black; in situ data applied with TES operator in blue; TES data in red. Bias, standard deviation (SD) and correlations $(R)$ for the comparison between blue and red are given. Error bar represents the error on the mean (standard variation within the grid bin divided by the square root of the number of observations).

with fairly good correlation coefficients $(R>0.6)$. Although small differences remain in each comparison, the standard deviation (SD) of their differences is consistent with the magnitude of the calculated mean errors.

\subsubsection{Seasonal variations over Mauna Loa}

We also perform a comparison of the TES multiyear monthly average within a grid box of $10^{\circ}$ by $10^{\circ}$ latitude/longitude centered at Mauna Loa $\left(19.5^{\circ} \mathrm{N}, 155.6^{\circ} \mathrm{W}\right)$ to the ground station measurements at Mauna Loa site (MLO), a highaltitude site within a global air-sampling network (Montzka et al., 2007). The measurements of OCS are from flasks filled with ambient air at the Mauna Loa Observatory at $\sim 3.4 \mathrm{~km}$ a.s.l. (above sea level) from a tower $40 \mathrm{~m}$ above ground level on the side of the Mauna Loa volcano. The measurement precision for OCS from flasks is typically less than $1 \%$. Flask samples are collected in mid-morning and typically represent free tropospheric air. The magnitude of the observed seasonal variation at this high-altitude surface site is about $9 \%$ (or $44 \mathrm{ppt}$ ). This variation and that derived from other NOAA flask measurements regularly made in the free troposphere (above $2 \mathrm{~km}$ a.s.l.) is relatively small compared to the seasonal variation observed at low-altitude continental sites in higher latitudes of the Northern Hemisphere (Montzka et al., 2007).

In Fig. 8g, we show OCS results by averaging the TES retrievals with at least 0.5 DOFs over Mauna Loa within a grid box of $10^{\circ}$ by $10^{\circ}$ for each month from 2006 to 2010 (red dots). The same quality flags used for the HIPPO comparisons are applied. The NOAA Mauna Loa monthly averages over the same period, from 2006 to 2010, at the surface site are plotted in black dots in Fig. 8g. The blue line is the MLO monthly averages after applying the TES operator. The comparison between red and blue suggests that with the TES limited sensitivity, e.g., the DOFs for OCS are between 0.5 and 1 , only about $20 \mathrm{ppt}$ of the seasonal variation that can be observed from space. TES retrieved monthly mean (red dots), however, varies consistently with the corresponding groundbased monthly mean. The error bar shows the error on the mean of TES monthly values. On average, the uncertainty of these TES monthly means is about $7 \mathrm{ppt}$ and SD of the differences is about 5 ppt. There is about -15 ppt bias, larger than the bias in HIPPO-TES comparisons, as expected because MLO data is a point measurement of the lower tropospheric OCS concentration near the surface at $3.4 \mathrm{~km}$ instead of a profile measurement as HIPPO data. 


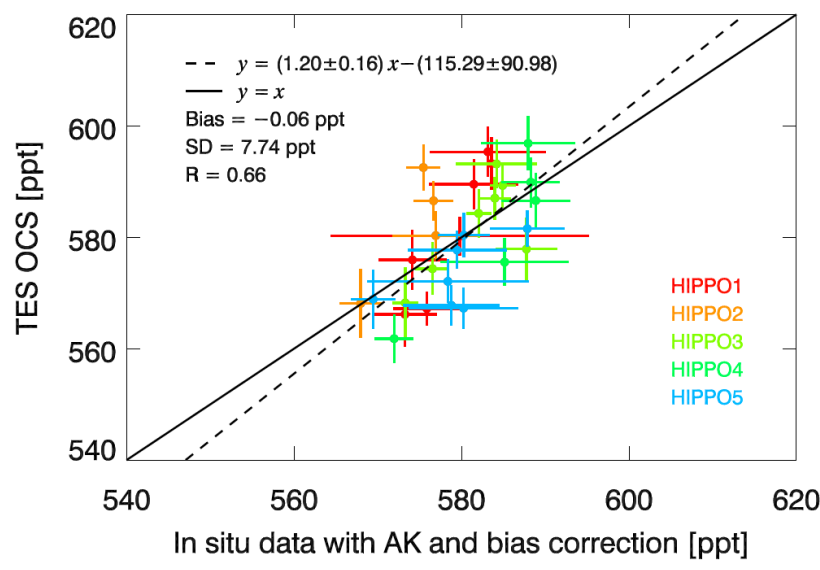

Fig. 9. The correlation plot of TES versus HIPPO in situ data with the TES operator. The dashed line shows the linear fit and the solid line is a one-to-one line for reference. The bias is close to zero because it has been removed by the TES operator. SD of the difference is $7.74 \mathrm{ppt}$ and $R$ is 0.66 . The color indicates the comparison to each HIPPO campaign. The error bar is the error on the mean.

\subsubsection{Comparison to all HIPPO data}

Figure 9 shows the correlation of TES monthly OCS to a corresponding HIPPO estimates convolved with the TES operator. TES OCS shows a fairly good correlation $(R=0.66)$ with these bias corrected in situ data, which were obtained with the TES operator during different months of the year. The bias has been removed using the TES operator and the calculated TES overall SD error is about 7.74 ppt. The estimated precision of these averaged TES OCS estimates is about $5 \mathrm{ppt}$ (the average of the total errors from single soundings divided by square root of the number of observations). The remaining difference between the calculated SD error and TES precision can be explained by (1) the averaging of TES data over several years whereas the OCS is expected to have some interannual variability, for example, due to El Niño-Southern Oscillation (ENSO); (2) additional variance because the retrieval problem is nonlinear or (3) because of bias or smoothing errors from the co-retrieved $\mathrm{CO}_{2}$ and $\mathrm{H}_{2} \mathrm{O}$ estimates (Fig. 6). Based on this comparison we would expect the accuracy of the TES OCS retrievals to have an upper bound of $5 \mathrm{ppt}$ (not including the bias likely due to spectroscopy) in order to explain the remaining difference between the precision and the overall SD error to HIPPO data.

The calculated error is well explained by the expected error and is less than the magnitude of the observed seasonal variation and latitudinal gradient from the aircraft and surface data. The maximum-minimum differences for both latitudinal and seasonal variations are in general more than 10 ppt. Therefore, with the current precision, TES multiyear monthly OCS is capable of detecting both latitudinal and seasonal variations. Table 1 summarizes comparisons for each data set by listing correlation coefficient $(R)$, bias, SD error

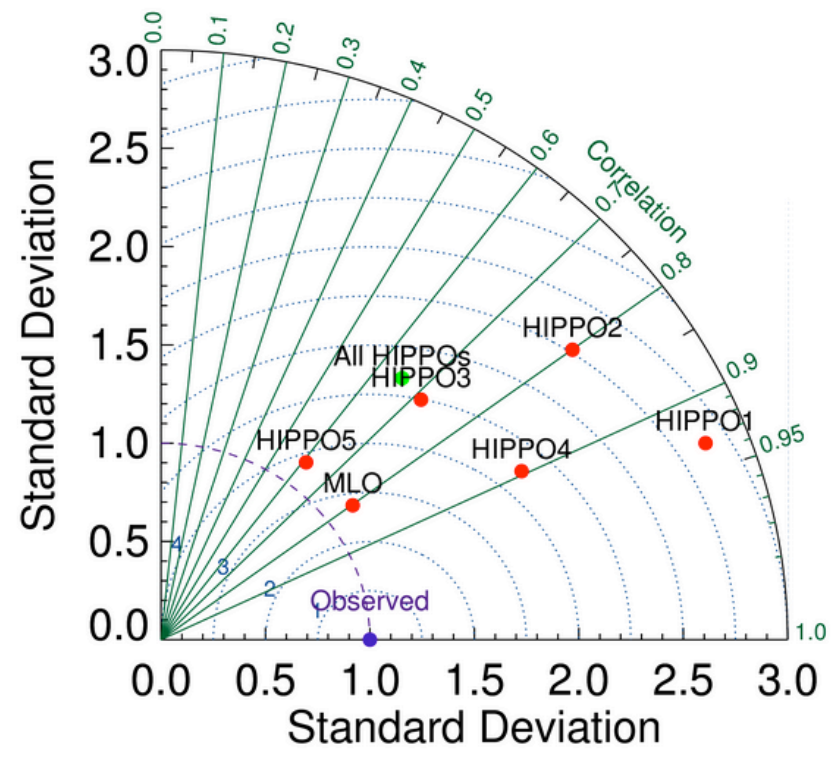

Fig. 10. Taylor diagram of TES OCS as compared to in situ data. The radius of the diagram is in units of the standard deviation of the observations of the in situ data and the angle indicates the correlation to the in situ data. Perfect agreement with in situ observations is always located at one standard deviation and correlation of 1 (purple dot). The distance to the purple dot indicates the error. Individual comparisons between TES and in situ data as in Fig. 8 are plotted as red dots and the comparisons of TES to all HIPPOs as green dots.

and TES precision. The Mauna Loa TES data has larger error bars than HIPPO-matching TES data simply because its sample size is much smaller than the number of TES data for corresponding HIPPO measurements.

A Taylor diagram in Fig. 10 shows the performance of the TES observed spatiotemporal pattern and variability compared to the processed in situ observations for different comparisons. The radius of the diagram is in the units of the standard deviation of the patterns observed from in situ data and the angle indicates the correlation to the in situ data. The perfect agreement with in situ observations is always located at 1 standard deviation and correlation of 1 (purple dot). The distance to the purple dot indicates the error. Individual comparisons between TES and in situ data as in Fig. 8 are plotted as red dots and the comparisons of TES to all HIPPOs as green dots. In general, correlations are at least more than 0.6 and TES always observes larger variability than in situ observations.

\section{Conclusions}

In this paper we describe an approach to retrieve atmospheric carbonyl sulfide from TES spectra over the ocean and evaluate the results against in situ data. The retrieved results are obtained by fitting the OCS absorption band ranging from 2034 to $2075 \mathrm{~cm}^{-1}$. Simultaneous retrieval of interfering 
species including water vapor, $\mathrm{CO}_{2}$, surface temperature, cloud optical depth and cloud pressure, based on the previous retrieved values, minimizes the impact of the systematic errors.

We carry out an initial assessment of the TES retrieval performance over ocean regions by comparing TES multiyear monthly averages at Mauna Loa with the corresponding ground-based observations (MLO). We also compared the multiyear monthly mean TES data across the Pacific between $35^{\circ} \mathrm{S}$ and $35^{\circ} \mathrm{N}$ with measurements made during the five HIPPO campaigns across this region.

The retrievals have maximum sensitivity between 300 and $500 \mathrm{hPa}$ but with DOFs that are typically less than 1.0. The typical uncertainties for a single observation, averaged over the troposphere, range from 50 to $80 \mathrm{ppt}$. However, the uncertainties are primarily driven by noise in the TES spectra and consequently, these observations can be averaged to reduce the error. The TES data are biased high by about $13 \%$, but when averaged over multiple years and after accounting for the TES OCS sensitivities and noise, these data can capture the seasonal and latitudinal variability of tropospheric OCS. A future algorithm will examine the variability of quantifying OCS over land; this algorithm will include an estimate of surface emissivity, which can vary strongly enough to influence the OCS retrieval. Care must therefore be taken to identify regions where emissivity variations are small enough to allow for an accurate estimate of OCS.

Acknowledgements. This work was carried out at the Jet Propulsion Laboratory, California Institute of Technology, under a contract with the National Aeronautics and Space Administration. We thank and acknowledge Steve Wofsy, Elliot Atlas, Benjamin R. Miller, Fred Moore, James Elkins, and all other HIPPO team members (the pilots, mechanics, technicians, and scientific crew) for making the HIPPO data available. HIPPO was supported by NSF grants ATM-0628575, ATM-0628519, and ATM-0628388, and by the National Center for Atmospheric Research (NCAR). NCAR is supported by the NSF. The authors also wish to thank Yuk Yung, Elliott Campbell, Joe Berry, and Ian Baker for helpful discussions.

Edited by: F. Boersma

\section{References}

Asaf, D., Rotenberg, E., Tatarinov, F., Dicken, U., Montzka, S. A., and Yakir, D.: Ecosystem Photosynthesis Inferred from Measurements of Carbonyl Sulphide Flux, Nat. Geosci., 6, 186-190, doi:10.1038/ngeo1730, 2013.

Barkley, M. P., Palmer, P. I., Boone, C. D., Bernath, P. F., and Suntharalingam, P.: Global distributions of carbonyl sulfide in the upper troposphere and stratosphere, Geophys. Res. Lett., 35, L14810, doi:10.1029/2008g1034270, 2008.

Beer, R.: TES on the Aura Mission: scientific objectives, measurements, and analysis overview, IEEE T. Geosci. Remote, 44, 1102-1105, doi:10.1109/TGRS.2005.863716, 2006.
Berry, J., Wolf, A., Campbell, J. E., Baker, I., Blake, N., Blake, D., Denning, A. S., Kawa, S. R., Montzka, S. A., Seibt, U., Stimler, K., Yakir, D., and Zhu, Z.: A coupled model of the global cycles of carbonyl sulfide and $\mathrm{CO}_{2}$ : A possible new window on the carbon cycle, J. Geophys. Res.-Biogeo., 118, 1-11, doi:10.1002/jgrg.20068, 2013.

Blonquist, J. M., Montzka, S. A., Munger, J. W., Yakir, D., Desai, A. R., Dragoni, D., Griffis, T. J., Monson, R. K., Scott, R. L., and Bowling, D. R.: The potential of carbonyl sulfide as a proxy for gross primary production at flux tower sites, J. Geophys. Res., 116, G04019, doi:10.1029/2011jg001723, 2011.

Bowman, K. W., Rodgers, C. D., Kulawik, S., Worden, J., Sarkissian, E., Osterman, G., Steck, T., Lou, M., Eldering, A., Shephard, M., Worder, H., Lampel, M., Clough, S., Brown, P., Rinsland, C., Gunson, M., and Beer, R.: Tropospheric emission spectrometer: retrieval method and error analysis, IEEE T. Geosci. Remote, 44, 1297-1307, doi:10.1109/TGRS.2006.871234, 2006.

Brühl, C., Lelieveld, J., Crutzen, P. J., and Tost, H.: The role of carbonyl sulphide as a source of stratospheric sulphate aerosol and its impact on climate, Atmos. Chem. Phys., 12, 1239-1253, doi:10.5194/acp-12-1239-2012, 2012.

Campbell, J. E., Carmichael, G. R., Chai, T., Mena-Carrasco, M., Tang, Y., Blake, D. R., Blake, N. J., Vay, S. A., Collatz, G. J., Baker, I., Berry, J. A., Montzka, S. A., Sweeney, C., Schnoor, J. L., and Stanier, C. O.: Photosynthetic control of atmospheric carbonyl sulfide during the growing season, Science, 322, 10851088, doi:10.1126/science.1164015, 2008.

Chin, M. and Davis, D. D.: A reanalysis of carbon sulfide as a source of stratosphere background sulfer aerosol, J. Geophys. Res., 100, 8993-9005, 1995.

Cutter, G. A., Cutter, L. S., and Filippino, K. C.: Sources and cycling of carbonyl sulfide in the Sargasso Sea, Limnol. Oceanogr., 49, 555-565, 2004.

Ko, M. K. W., Poulet, G., Blake, D. R., Boucher, O., Burkholder, J. H., Chin, M., Cox, R. A., George, C., Graf, H.-F., Holton, J. R., Jacob, D. J., Law, K. S., Lawrence, M. G., Midgley, P. M., Seakins, P. W., Shallcross, D. E., Strahan, S. E., Wuebbles, D. J., and Yokouchi, Y.: Very short-lived halogen and sulfur substances, Scientific Assessment of Ozone Depletion, Global Ozone Research and Monitoring Project-Report No. 47, World Meteorological Organization, Geneva, 2003.

Kulawik, S. S., Worden, H., Osterman, G., Luo, M., Beer, R., Kinnison, D. E., Bowman, K. W., Worden, J., Eldering, A., Lampel, M., Steck, T., and Rodger, C. D.: TES atmospheric profile retrieval characterization: an orbit of simulated observations, IEEE T. Geosci. Remote, 44, 1324-1333, doi:10.1109/TGRS.2006.871207, 2006.

Kulawik, S. S., Jones, D. B. A., Nassar, R., Irion, F. W., Worden, J. R., Bowman, K. W., Machida, T., Matsueda, H., Sawa, Y., Biraud, S. C., Fischer, M. L., and Jacobson, A. R.: Characterization of Tropospheric Emission Spectrometer (TES) $\mathrm{CO}_{2}$ for carbon cycle science, Atmos. Chem. Phys., 10, 5601-5623, doi:10.5194/acp-10-5601-2010, 2010.

Mahieu, E., Rinsland, C. P., Zander, R., Duchatelet, P., and Servais, C.: Tropospheric and stratospheric carbonyl sulfide (OCS): Long-term trends and seasonal cycles above the Jungfraujoch station, The Sixth European Symposium on Stratospheric Ozone, 2-6 September, Goteborg, Sweden, 309-312, 2003. 
Montzka, S. A., Aydin, M., Battle, M., Butler, J. H., Saltzman, E. S., Hall, B. D., Clarke, A. D., Mondeel, D. J., and Elkins, J. W.: A 350-year atmospheric history for carbonyl sulfide inferred from Antarctic firn air and air trapped in ice, J. Geophys. Res., 109, D22302, doi:10.1029/2004jd004686, 2004.

Montzka, S. A., Calvert, P., Hall, B. D., Elkins, J. W., Conway, T. J., Tans, P. P., and Sweeney, C.: On the global distribution, seasonality, and budget of atmospheric carbonyl sulfide (COS) and some similarities to $\mathrm{CO}_{2}$, J. Geophys. Res., 112, D09302, doi:10.1029/2006jd007665, 2007.

Notholt, J., Kuang, Z., Rinsland, C. P., Toon, G. C., Rex, M., Jones, N., Albrecht, T., Deckelmann, H., Krieg, J., Weinzierl, C., Bingemer, H., Weller, R., and Schrems, O.: Enhanced upper tropical tropospheric COS: impact on the stratospheric aerosol layer, Science, 300, 307-310, doi:10.1126/science.1080320, 2003.

Notholt, J., Bingemer, H., Berresheim, H., Holton, J. R., Kettle, A. J., Mahieu, E., and Montzka, S.: Precursor gas measurement, SPARC Assessment of Stratospheric Aerosol Properties, SPARC Scientific Steering Group, Zurich, 2006.

Rinsland, C. P., Goldman, A., Mahieu, E., Zander, R., Notholt, J., Jones, N. B., Griffith, D. W. T., Stephen, T. M., and Chiou, L. S.: Ground-based infrared spectroscopic measurements of carbonyl sulfide: Free tropospheric trends from a 24-year time series of solar absorption measurements, J. Geophys. Res., 107, 4657, doi:10.1029/2002jd002522, 2002.

Rinsland, C. P., Chiou, L., Mahieu, E., Zander, R., Boone, C. D., and Bernath, P. F.: Measurements of long-term changes in atmospheric OCS (carbonyl sulfide) from infrared solar observations, J. Quant. Spectrosc. Ra., 109, 2679-2686, doi:10.1016/j.jqsrt.2008.07.008, 2008.

Rodgers, C. D.: Inverse Methods for Atmospheric Sounding: Theory and Practice, World Scientific, London, 256 pp., 2000.

Shephard, M. W., Cady-Pereira, K. E., Luo, M., Henze, D. K., Pinder, R. W., Walker, J. T., Rinsland, C. P., Bash, J. O., Zhu, L., Payne, V. H., and Clarisse, L.: TES ammonia retrieval strategy and global observations of the spatial and seasonal variability of ammonia, Atmos. Chem. Phys., 11, 10743-10763, doi:10.5194/acp-11-10743-2011, 2011.

Suntharalingam, P., Kettle, A. J., Montzka, S. M., and Jacob, D. J.: Global 3-D model analysis of the seasonal cycle of atmospheric carbonyl sulfide: Implications for terrestrial vegetation uptake, Geophys. Res. Lett., 35, L19801, doi:10.1029/2008g1034332, 2008.
Verma, S., Worden, J., Pierce, B., Jones, D. B. A., Al-Saadi, J., Boersma, F., Bowman, K., Eldering, A., Fisher, B., Jourdain, L., Kulawik, S., and Worden, H.: Ozone production in boreal fire smoke plumes using observations from the Tropospheric Emission Spectrometer and the Ozone Monitoring Instrument, J. Geophys. Res.-Atmos., 114, D02303, doi:10.1029/2008JD010108, 2009.

Watts, S. F.: The mass budgets of carbonyl sulfide, dimethyl sulfide, carbon disulfide and hydrogen sulfide, Atmos. Environ., 34, 761799, 2000.

Wofsy, S. C., Team, H. S., Cooperating, M., and Satellite, T.: HIAPER Pole-to-Pole Observations (HIPPO): fine-grained, globalscale measurements of climatically important atmospheric gases and aerosols, Philos. Trans. R. Soc. A, 369, 2073-2086, doi:10.1098/rsta.2010.0313, 2011.

Wohlfahrt, G., Brilli, F., Hortnagl, L., Xu, X., Bingemer, H., Hansel, A., and Loreto, F.: Carbonyl sulfide (COS) as a tracer for canopy photosynthesis, transpiration and stomatal conductance: potential and limitations, Plant Cell Environ., 35, 657667, doi:10.1111/j.1365-3040.2011.02451.x, 2012.

Worden, H. M., Deeter, M. N., Edwards, D. P., Gille, J. C., Drummond, J. R., and Nédélec, P.: Observations of near-surface carbon monoxide from space using MOPITT multispectral retrievals, J. Geophys. Res., 115, D18314, doi:10.1029/2010jd014242, 2010.

Worden, J., Kulawik, S. S., Shephard, M., Clough, S. A., Worden, H., Bowman, K., and Goldman, A.: Predicted errors of tropospheric emission spectrometer nadir retrievals from spectral window selection, J. Geophys. Res., 109, D09308, doi:10.1029/2004jd004522, 2004.

Worden, J., Bowman, K., Noone, D., Beer, R., Clough, S., Eldering, A., Fisher, B., Goldman, A., Gunson, M., Herman, R., Kulawik, S. S., Lampel, M., Luo, M., Osterman, G., Rinsland, C., Rodgers, C., Sander, S., Shephard, M., and Worden, H.: Tropospheric Emission Spectrometer observations of the tropospheric $\mathrm{HDO} / \mathrm{H}_{2} \mathrm{O}$ ratio: Estimation approach and characterization, J. Geophys. Res., 111, D09308, doi:10.1029/2005jd006606, 2006.

Worden, J., Wecht, K., Frankenberg, C., Alvarado, M., Bowman, K., Kort, E., Kulawik, S., Lee, M., Payne, V., and Worden, H.: $\mathrm{CH}_{4}$ and $\mathrm{CO}$ distributions over tropical fires during October 2006 as observed by the Aura TES satellite instrument and modeled by GEOS-Chem, Atmos. Chem. Phys., 13, 3679-3692, doi:10.5194/acp-13-3679-2013, 2013. 